\title{
Platelet-rich plasma does not reduce skeletal muscle fibrosis after distraction osteogenesis
}

\author{
Ichiro Tonogai", Fumio Hayashi, Toshiyuki Iwame, Tomoya Takasago, Tetsuya Matsuura and Koichi Sairyo
}

\begin{abstract}
Background: Skeletal muscle fibrosis caused by an increase in collagen deposition often occurs after distraction osteogenesis. Although studies are available reporting the effects of platelet-rich plasma (PRP) on tissue healing following injury, current findings remain controversial. This study focused on determining whether PRP reduces skeletal muscle fibrosis caused by distraction osteogenesis.
\end{abstract}

Methods: Tibial osteotomies were performed on 8-week-old wild type mice, and tibiae were distracted at a rate of $0.42 \mathrm{~mm} /$ day for 2 weeks, starting 1 week after osteotomy. Immediately after distraction was completed (3 weeks after osteotomy), PRP or phosphate buffered saline (as a sham) was injected into the gastrocnemius (GC) muscle. The GC muscles were harvested and analyzed.

Results: The amount and area of collagenous tissue increased in both the PRP and control groups following distraction osteogenesis, but the changes were not significantly different between both groups at all time points $(p=0.89,0.45,0.33$ and 0.52 at 4, 6, 8 and 10 weeks).

Conclusion: From this study, our results suggest that PRP did not significantly reduce skeletal muscle fibrosis due to distraction osteogenesis.

Keywords: Platelet-rich plasma, Distraction osteogenesis, Skeletal muscle, Fibrosis

\section{Background}

Distraction osteogenesis is a useful treatment for trauma and musculoskeletal disorders that result in limb length discrepancy and short stature (Ilizarov 1990). However, distraction osteogenesis causes a specific kind of skeletal muscle damage (Williams et al. 1999; Williams et al. 1998; Williams et al. 2001; De Deyne et al. 2000; Antoci et al. 2006; Tonogai et al. 2015). This extremely severe skeletal muscle damage is characterized by repeated regular and gradual distraction of the muscle during distraction phase (Tonogai et al. 2015). Fibroblasts migrate to the damaged site and proliferate, and fibrous tissue is formed by increased production of collagen (Tonogai et al. 2015). Therefore, fibrosis often results in common clinical complications such as skeletal muscle contracture (Antoci et al. 2006; Paley 1999).

\footnotetext{
* Correspondence: i.tonogai@tokushima-u.ac.jp

Department of Orthopedics, Institute of Health Biosciences, Tokushima

University Graduate School, 3-18-15 Kuramoto, Tokushima 770-8503, Japan
}

Platelet-rich plasma (PRP), an easily obtainable product, is the plasma fraction derived from a person's own blood, and it contains high concentrations of platelets including growth factors (GFs), which are known to play a critical role in tissue healing (Molloy et al. 2003; Anitua et al. 2006; Wang et al. 2006; DeLong et al. 2012). However, not all studies have found positive outcomes of PRP (Nin et al. 2009; de Vos et al. 2010; de Jonge et al. 2011; Schepull et al. 2011). In terms of skeletal muscle, some authors report that PRP enhances the skeletal muscle healing process (Menetrey et al. 2000; Huard et al. 2002; WrightCarpenter et al. 2004; Järvinen et al. 2007; Sanchez et al. 2007; Cunha et al. 2014; Contreras-Muñoz et al. 2017), while Harris et al. report the development of thrombosis, necrosis, and calcium deposition histologically at intramuscular PRP injection sites and thus the potential for negative effects of PRP injections (Harris et al. 2012), and Kelc et al. report concerns that PRP injection may lead to fibrosis (Kelc et al. 2015). 
Some articles describe the osteogenic effect of PRP injection during osteogenesis (Kitoh et al. 2004; Ali et al. 2015). However, no studies have investigated the effect of PRP on skeletal muscle fibrosis caused by distraction osteogenesis, although we reported the evaluation of the skeletal muscle after distraction osteogenesis in mice without any additional intervention such as PRP administration (Tonogai et al. 2015). We hypothesized that PRP has favorable effects on skeletal muscle fibrosis following distraction osteogenesis, and in this study we investigated specifically whether PRP reduces skeletal muscle fibrosis and what ratio PRP influences on skeletal muscle fibrosis following distraction osteogenesis in mice.

\section{Methods}

\section{Experimental animals}

Eight-week-old wild-type (WT) male (C57BL/6xDBA/2) F1 (BDF1) mice (weight 23-27 g) purchased from Japan SLC Inc. (Shizuoka, Japan), were used in this study. All animal experiments were approved by the Animal Care and Use Committee of Tokushima University Graduate School and were performed according to the Guidelines for the Care and Use of Laboratory Animals at Tokushima University Graduate School.

\section{Distraction osteogenesis}

The operative procedure was performed with an external fixator for limb lengthening as described previously (Tonogai et al. 2015). The external fixator consisted of 2 open aluminum rings, 2 stainless steel screws, and 6 nuts. Mice were anesthetized with an intraperitoneal injection of $2.5 \%$ tribromoethanol. The external fixator was applied with super glue to the right tibia, using two $27 \mathrm{G}$ needles for each proximal and distal ring. A transverse osteotomy was performed with a No. 11 scalpel blade at the mid-shaft of the tibia between the 2 rings without any additional soft tissue damage. The wound was closed with 5-0 nylon suture after completion of the osteotomy. The mice were allowed free unrestricted weightbearing.

The protocol of the distraction osteogenesis is shown in Fig. 1. We performed distraction osteogenesis of the right hind limbs for total 80 mice, and assigned 40 mice into non-PRP group and the remaining 40 mice into PRP group, and 10 mice in each group were sacrificed at 4, 6, 8 , and 10 weeks after osteotomy ( $n=10 /$ group/week). Briefly, after a lag phase of 1 week, distraction was carried out at a rate of $0.21 \mathrm{~mm}$ every $12 \mathrm{~h}$ for 2 weeks, because a faster rate might cause peroneal nerve palsy resulting in denervation change of the muscle and a slower rate might lead to less muscle fibrosis. The length of the distraction gap seen on X-ray was approximately $6 \mathrm{~mm}$ at the end of the distraction phase. PRP $40 \mu \mathrm{l}$ was injected directly into each distracted right gastrocnemius (GC) muscle in a total of 40 mice (PRP group) immediately after completing distraction osteogenesis (3 weeks after osteotomy), because muscle fibrosis was very severe at that time point as we reported previously (Tonogai et al. 2015). The injection site was prepped in a typical sterile fashion, and the needle was exactly inserted through the skin into the belly of the right GC muscle under ultrasound. Half of the volume, $20 \mu \mathrm{l}$, was injected into the medial right $\mathrm{GC}$, and the remaining half was injected into the lateral right GC. For the sham group, $40 \mu \mathrm{l}$ phosphate buffered saline (PBS) was injected into each right distracted GC muscle in a total of 40 mice in the same manner (non-PRP group).

\section{PRP preparation}

We prepared allogenic PRP-containing leukocytes (L-PRP) using the BS Medical Platelet Concentration System (BS Medical, Tokyo, Japan), which was specialized for small animals like mouse, following the manufacturer's instructions. L-PRP were prepared in a two-step centrifugation process.

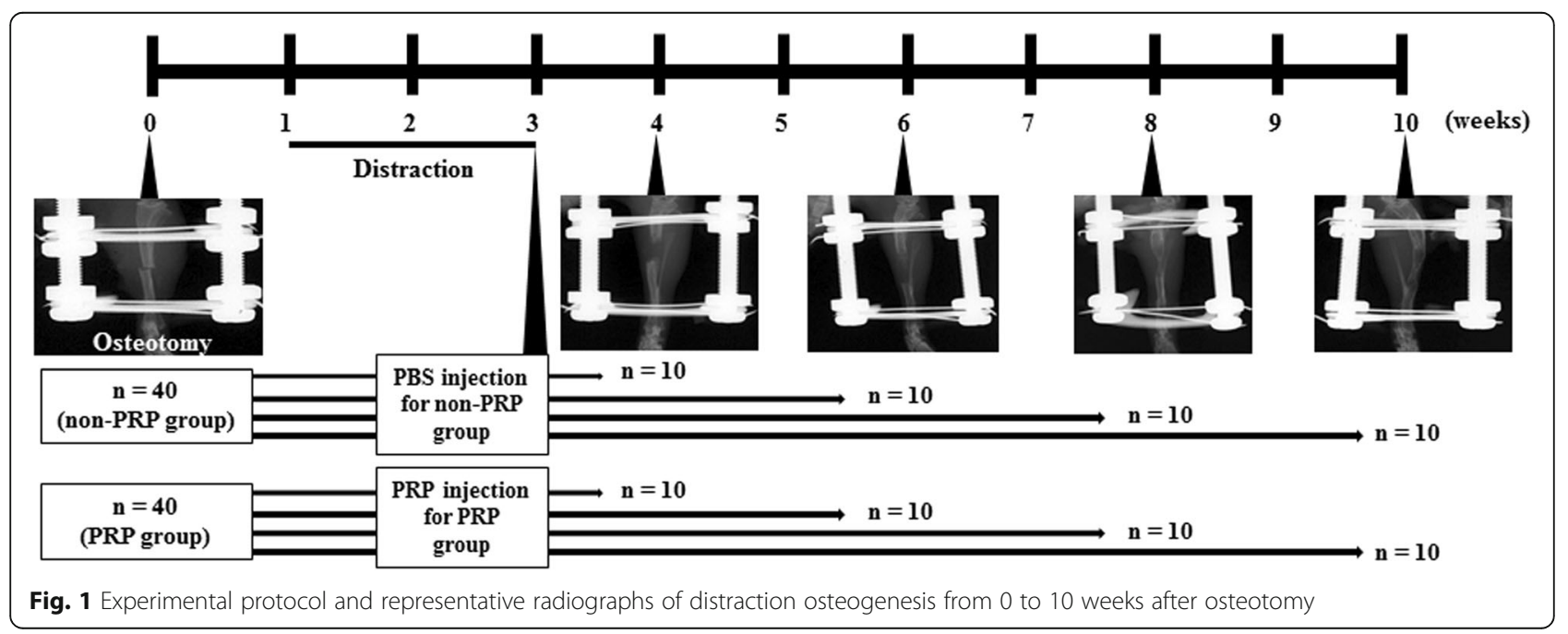


Briefly, $500 \mu \mathrm{l}$ was withdrawn via intra-cardiac puncture from 1 adult male mouse (11 weeks old). Then, $5 \mathrm{ml}$ whole blood from 10 mice was pooled and collected in a blood tube including $0.5 \mathrm{ml}$ acid citrate dextrose (ACD) solution which was anticoagulant. The whole blood was centrifuged at $550 \mathrm{G}(1800 \mathrm{rpm})$ for $8 \mathrm{~min}$, resulting in the formation of 3 layers: plasma, buffy coat including PRP component, and red blood cell (RBC) layer (Fig. 2). As much as possible, the top two-thirds of the supernatant was obtained for PRP preparation and was centrifuged again at $380 \mathrm{G}(1500 \mathrm{rpm})$ for $6 \mathrm{~min}$, resulting in the formation of 3 layers: plasma, buffy coat including PRP component, and a small RBC layer. The buffy coat including $500 \mu \mathrm{l}$ PRP was carefully isolated and harvested from the tube. In this study, a total of $20 \mathrm{ml}$ of whole blood was collected from 40 adult male 11-week-old mice, and a total of $2 \mathrm{ml}$ PRP was obtained. PRP was used immediately after preparation rather than storing for later use, to minimize any effects of prolonged storage or freeze/thaw cycles and in accordance with how it is typically prepared and applied clinically (Delos et al. 2014). Next, $40 \mu \mathrm{l}$ of PRP was injected into each GC of the distracted hind limb $(20 \mu \mathrm{l}$ into the medial GC and $20 \mu \mathrm{l}$ into the lateral GC) in a total of 40 mice (PRP group) just after distraction osteogenesis finished. The volume of injection was consistent with another study using a mouse muscle injury model (Qu and Huard 2000; Ota et al. 2011;

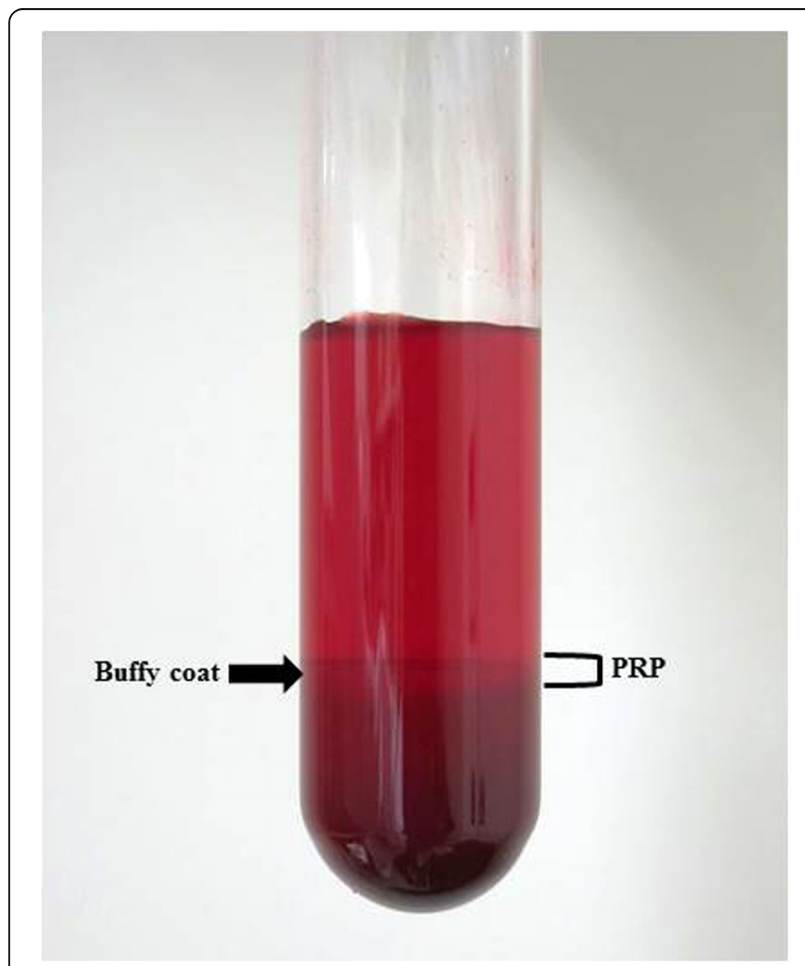

Fig. 2 Whole blood in a tube containing ACD, which was anticoagulant, after centrifuging shows 3 layers comprising clear plasma, buffy coat including PRP component, and RBC layer
Terada et al. 2013). The remaining $400 \mu \mathrm{l}$ PRP was subjected to measurement, consisting of white blood cell (WBC), RBC, and platelet counts, and assessment of the GFs vascular endothelial growth factor (VEGF), plateletderived growth factor-AB (PDGF-AB), and transforming growth factor- $\beta 1$ (TGF- $\beta 1)$.

\section{Assessment of WBC, RBC, platelets, and GFs}

WBC, RBC, and platelet counts in whole blood and PRP were determined using an automated cell counter to determine whether platelets were enriched in PRP. Concentrations of VEGF (R\&D Systems, Minneapolis, MN, US), PDGF-AB (R\&D Systems, Minneapolis, MN, US), and TGF- $\beta 1$ (R\&D Systems, Minneapolis, MN, US) were determined by enzyme-linked immunosorbent assay (ELISA) to detect and quantify the presence of GFs. Analyses were then performed according to the manufacturer's instructions. Briefly, samples and standards were added to $96 \mathrm{GF}$ antibody-coated well plates. After incubation and removal of unbound substances, a secondary antibody was added. This was followed by further washing and incubation with a substrate. The color reaction was stopped, and optical density was measured at a wavelength of $495 \mathrm{~nm}$.

\section{Tissue preparation}

We chose GC muscle because we could obtain enough muscle volume to evaluate in histological analysis and hydroxyproline assessment, although tibialis antetior (TA) muscle also underwent fibrosis. Right GC muscles in each group were harvested, weighed, and flash frozen in liquid nitrogen-precooled isopentane at 4, 6, 8, and 10 weeks after osteotomy ( $n=10 /$ group/week). Then, all samples were cut longitudinally in the middle of the right $\mathrm{GC}$ muscle and divided into medial and lateral parts. The medial GC muscles from each group per week were used for histological analysis ( $n=10 /$ group/week). The lateral GC muscles from each group per week were used for hydroxyproline assay to assess collagen content ( $n=10 /$ group/week).

\section{Histological analysis}

A cryostat was used to make $10-\mu \mathrm{m}$ thick transverse sections of the central part of the belly of the GC muscle. Sections were mounted on MAS-coated slides (Matsunami Glass Industries, Osaka, Japan) and fixed in ice-cold acetone for $10 \mathrm{~min}$. Sections were stained with Masson's trichrome for histological examination of skeletal muscle fibrosis. The degree of fibrosis was evaluated in Mason's trichrome staining images. Fibrotic blue area was measured in all fields using the image analysis software WinROOF (Mitani Corporation, Fukui, Japan), and was calculated to estimate the percentage of fibrosis development. 


\section{Hydroxyproline assay for collagen content}

Hydroxyproline is a major constituent of collagen and is highly expressed in fibrous tissue (Mu et al. 2010). Total hydroxyproline content was determined in the GC muscle using a colorimetric assay kit (BioVision, Milpitas, CA) to evaluate fibrotic changes in the distracted GC muscles, as described previously (Tonogai et al. 2015). Briefly, GC muscles were hydrolyzed in $12 \mathrm{~N} \mathrm{HCl}$ at $120{ }^{\circ} \mathrm{C}$ for $3 \mathrm{~h}$. After hydrolysis, samples were neutralized and treated with chloramine $\mathrm{T}$ solution for $5 \mathrm{~min}$ at room temperature followed by dimethylamine borane solution for $90 \mathrm{~min}$ at $60{ }^{\circ} \mathrm{C}$. Absorbance was measured at $560 \mathrm{~nm}$. Hydroxyproline concentration was determined by comparison with a standard curve prepared from pure hydroxyproline of known concentrations.

\section{Statistical analysis}

Data are expressed as mean \pm standard error of mean (SEM). Unpaired Student's t-test was used to analyze differences between the PRP and non-PRP groups at 4 , 6,8 , and 10 weeks after osteotomy. $P<.05$ was considered statistically significant.

\section{Results}

\section{Hematological analysis of WBC, RBC, and platelets}

The WBC count was approximately 2.5 times higher in PRP $(11,200 / \mu \mathrm{l})$ than in whole blood $(4500 / \mu \mathrm{l})$, indicating that the prepared PRP was actually L-PRP (Table 1). The RBC count was very low in PRP $\left(4 \times 10^{4} / \mu \mathrm{l}\right)$ compared with whole blood $\left(757 \times 10^{4} / \mu \mathrm{l}\right.$; Table 1$)$. The platelet count was approximately 7.7 times higher in PRP $(162 \times$ $\left.10^{4} / \mu \mathrm{l}\right)$ than in whole blood $\left(21 \times 10^{4} / \mu \mathrm{l}\right)($ Table 1$)$.

\section{Measurement of GFs using ELISAs}

The concentration of VEGF, PDGF-AB, and TGF- $\beta 1$ were all higher in PRP than in plasma (Table 2). VEGF was approximately 1.7 times higher at $69.7 \mathrm{pg} / \mathrm{ml}$; PDGF-AB was approximately 3.4 times higher at $9.8 \mathrm{ng} / \mathrm{ml}$; and TGF- $\beta 1$ was approximately 7.4 higher at $700.2 \mathrm{ng} / \mathrm{ml}$.

\section{Muscle wet weight}

We evaluated muscle wet weight, because it included moisture reflecting muscle edema. Wet weight of the GC muscles in the non-PRP and PRP groups decreased at 4 weeks after osteotomy $(0.114 \pm 0.002 \mathrm{~g}$ and $0.116 \pm$ $0.004 \mathrm{~g}$, respectively) and then gradually increased from

Table $1 \mathrm{WBC}$, RBC, and platelet counts in whole blood and PRP

\begin{tabular}{llll}
\hline & WBC $(/ \mu l)$ & RBC $\left(\times 10^{4} / \mu l\right)$ & Platelet $\left(\times 10^{4} / \mu l\right)$ \\
\hline Whole blood & 4500 & 757 & 21 \\
PRP & 11,200 & 9 & 162 \\
\hline
\end{tabular}

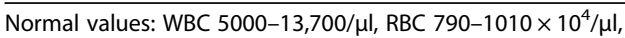
Platelet $60-120 \times 10^{4} / \mu \mathrm{l}$

$W B C$ white blood cell, $R B C$ red blood cell, $P R P$ platelet-rich plasma
Table 2 Concentration of VEGF, PDGF-AB, and TGF- $\beta 1$ in plasma and PRP

\begin{tabular}{llll}
\hline & VEGF $(\mathrm{pg} / \mathrm{ml})$ & PDGF-AB $(\mathrm{ng} / \mathrm{ml})$ & TGF- $\beta 1(\mathrm{ng} / \mathrm{ml})$ \\
\hline Plasma & 41.6 & 2.9 & 94.0 \\
PRP & 69.7 & 9.8 & 700.2 \\
\hline
\end{tabular}

VEGF vascular endothelial growth factor, $P D G F-A B$ platelet-derived growth factor- $A B, T G F-\beta 1$ transforming growth factor- $\beta 1$, PRP platelet-rich plasma

6 weeks (Fig. 3). Muscle weight improved to $0.160 \pm$ $0.009 \mathrm{~g}$ in the non-PRP group and $0.161 \pm 0.006 \mathrm{~g}$ in PRP group at 8 weeks, and to $0.155 \pm 0.005 \mathrm{~g}$ and 0.151 $\pm 0.007 \mathrm{~g}$, respectively, at 10 weeks. Thus, findings at 8 and 10 weeks were almost the same as the 0 -week level in both groups (Fig. 3). Weight in the PRP group did not differ significantly from that of the non-PRP group at any time point $(p=0.68,0.91,0.89$ and 0.46 at $4,6,8$ and 10 weeks).

\section{Fibrosis}

Masson's trichrome staining of representative images of non-PRP and groups PRP are shown in Fig. 4a. The appearance of severely fibrotic areas was similar in both groups at 4 weeks after osteotomy. The area of collagen deposition gradually decreased but persisted in both groups at 6,8 , and 10 weeks, at similar levels in both groups. The ratio of the fibrotic area to the total cross-sectional area was of the GC muscles in both groups remarkably increased at 4 weeks after osteotomy (non-PRP: $44.6 \pm 1.5 \%$; PRP: $43.7 \pm 1.5 \%$ ) and then gradually decreased at 6,8 , and 10 weeks (Fig. 4b). At 6, 8, and 10 weeks, there were no significant differences between the non-PRP and PRP groups $(30.3 \pm 0.6 \%$ vs $31.1 \pm 1.4 \%$, $p=0.73 ; 26.6 \pm 1.1 \%$ vs $24.6 \pm 1.2 \%, p=0.35$; and $22.3 \pm$ $1.0 \%$ vs $21.1 \pm 0.8 \%, p=0.49$, respectively; Fig. $4 \mathrm{~b}$ ).

The total hydroxyproline content of the GC muscles in both groups remarkably increased at 4 weeks after osteotomy (non-PRP: $4.39 \pm 0.08 \mu \mathrm{g} / \mathrm{mg}$ tissue; PRP: $4.21 \pm$ $0.07 \mu \mathrm{g} / \mathrm{mg}$ tissue) and then gradually decreased at 6,8 , and 10 weeks (Fig. 4c), consistent with the findings of Masson's trichrome staining. At 6,8 , and 10 weeks, there were no significant differences between the non-PRP and PRP groups $(2.80 \pm 0.06 \mu \mathrm{g} / \mathrm{mg}$ tissue vs $3.00 \pm 0.05 \mu \mathrm{g} / \mathrm{mg}$ tissue, $p=0.45 ; 2.72 \pm 0.17 \mu \mathrm{g} / \mathrm{mg}$ tissue vs $2.57 \pm 0.09 \mu \mathrm{g} / \mathrm{mg}$ tissue, $p=0.33$; and $2.47 \pm 0.08 \mu \mathrm{g} / \mathrm{mg}$ tissue vs $2.41 \pm$ $0.09 \mu \mathrm{g} / \mathrm{mg}$ tissue, $p=0.52$, respectively; Fig. 4c).

\section{Discussion}

This study, which was designed to investigate whether PRP reduced skeletal muscle fibrosis after distraction osteogenesis, found that distraction osteogenesis caused fibrous tissue formation in the GC muscles in the non-PRP and PRP groups. This fibrosis was remarkably increased at 4 weeks after osteotomy and subsequently decreased but persisted in both groups at 6,8 , and 10 weeks. 


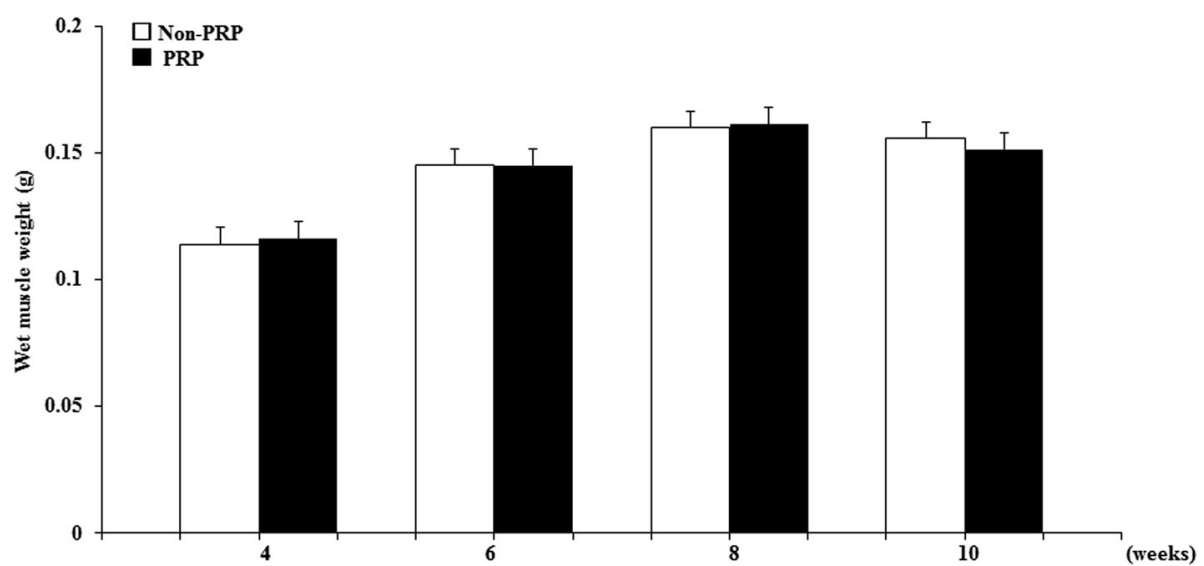

Fig. 3 Time course of changes in wet weight of GC muscles of the non-PRP and PRP groups at 4, 6, 8, and 10 weeks after osteotomy. Data represent mean \pm SEM ( $n=10 /$ group/week)

Although gradual decrease of fibrosis at 6,8 , and 10 weeks reflected muscle remodeling or healing as we reported previously (Tonogai et al. 2015), we found no significant differences in total hydroxyproline content, indicative of skeletal muscle fibrosis, between the non-PRP and PRP groups at any time point.

Although distraction osteogenesis does not directly damage muscle such as attack injury, distraction osteogenesis causes severe skeletal muscle damage by pulling strength (Tonogai et al. 2015). We initially expected that PRP might significantly reduce skeletal muscle fibrosis after distraction osteogenesis. However, our study showed no positive effect on muscle following distraction osteogenesis after treatment with PRP, similar to the findings of (Delos et al. 2014). They reported a high percentage of fibrous tissue in the PRP group compared with the control group in a rat GC contusion model. We are unable to clearly explain this observation, but various factors may be involved in the process. A possible reason could be that our distraction osteogenesis model involved more severe muscle damage than simple muscle injury. Although PRP might be effective in slight or mild skeletal muscle injury, our results might suggest that severe skeletal muscle damage during osteogenesis exceeds the tissue healing function of PRP.

PRP contains various GFs. For examples, PDGF stimulates mitogenesis of mesenchymal cells and chemotaxis (Hammond et al. 2009). VEGF leads to increased angiogenesis and decreased fibrosis in injured skeletal muscle (Deasy et al. 2009; Ranzato et al. 2009). However, besides the beneficial effects, PRP also contains significantly higher concentrations of TGF- $\beta 1$. TGF- $\beta 1$ is a key factor in the development of fibrosis (Border and Noble 1994) because it has the ability to stimulate collagen synthesis and fibroblast proliferation contributes to increased collagen deposition (Ignotz and Massague 1986). Therefore,
PRP containing TGF- $\beta 1$ might potentially stimulate skeletal muscle fibrosis (Massagué et al. 1986; Allen and Boxhorn 1989; Li and Huard 2002; Borrione et al. 2010; Visser et al. 2010), although there are reports that PRP-treated muscles showed reduction of fibrosis (Gigante et al. 2012; Gigante et al. 2014; Cianforlini et al. 2015). Nevertheless, an increase in fibrosis can accelerate the fibrotic healing process after tendon and ligament injuries (Hildebrand and Frank 1998; Mishra et al. 2009; Beye et al. 2008; Fallouh et al. 2010; Huang and Whang 2010; Iqbal et al. 2011), with the presence of high concentrations of TGF- $\beta 1$ in PRP potentially promoting fibrosis in injured skeletal muscle. Conversely, $\mathrm{Li}$ et al. reported that neutralizing TGF- $\beta 1$ in PRP reduced muscle fibrosis, and Terada et al. and Huard J et al. also reported that PRP injection and administration of losartan (an antifibrotic agent) decreased muscle fibrosis in an animal muscle injury model (Huard et al. 2002; Terada et al. 2013; Li et al. 2016). Blocking of factors that cause fibrosis like TGF- $\beta 1$ in PRP might be beneficial.

We selected L-PRP because it can be beneficial, stimulating the immune response against infections (Cieslik-Bielecka et al. 2007; Moojen et al. 2008); promoting chemotaxis, proliferation, and differentiation of cells; and inducing angiogenesis (Wrotniak et al. 2007). In contrast, Zhou $\mathrm{H}$ al. reported that L-PRP may be detrimental to the healing of injured tissue because it induces catabolic and inflammatory effects on cells and may prolong the effects in healing tissue, while pure-PRP (P-PRP) may result in formation of excessive scar tissue due to the strong potential of P-PRP to induce inordinate cellular anabolic effects when used to treat acutely injured tissue (Zhou et al. 2015). The presence or absence of WBC might also affect the results because the exact role of leukocytes in PRP is unclear as yet. Further studies are required to clarify the ideal PRP formulations including WBC. 


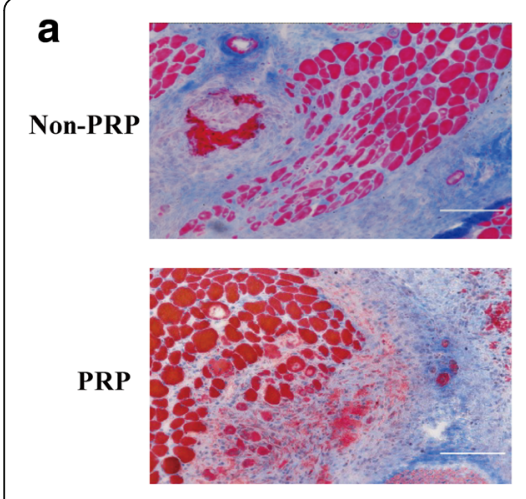

4
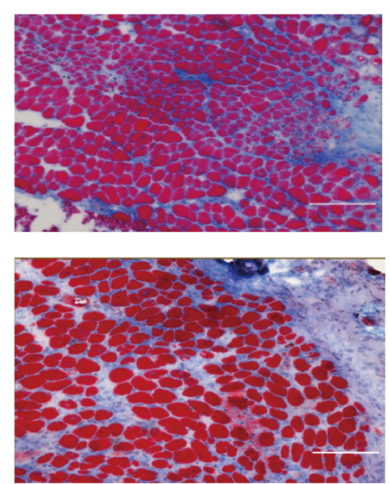

6
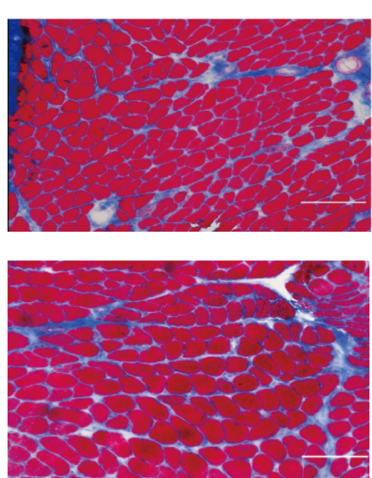

8
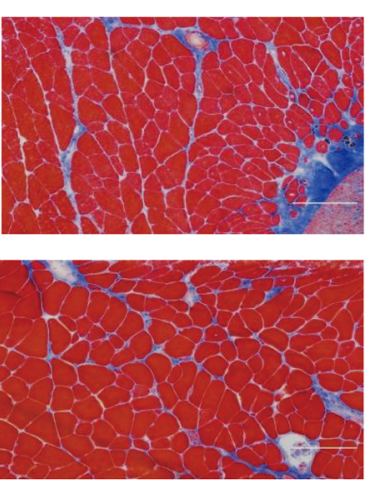

10

(weeks)

b

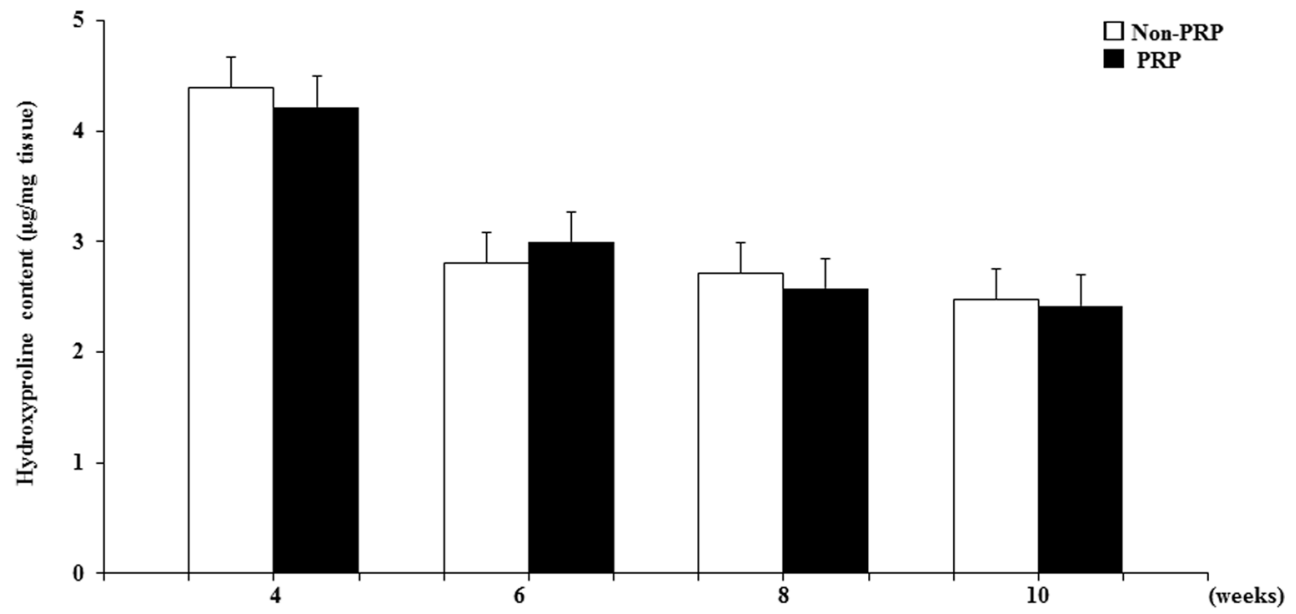

C

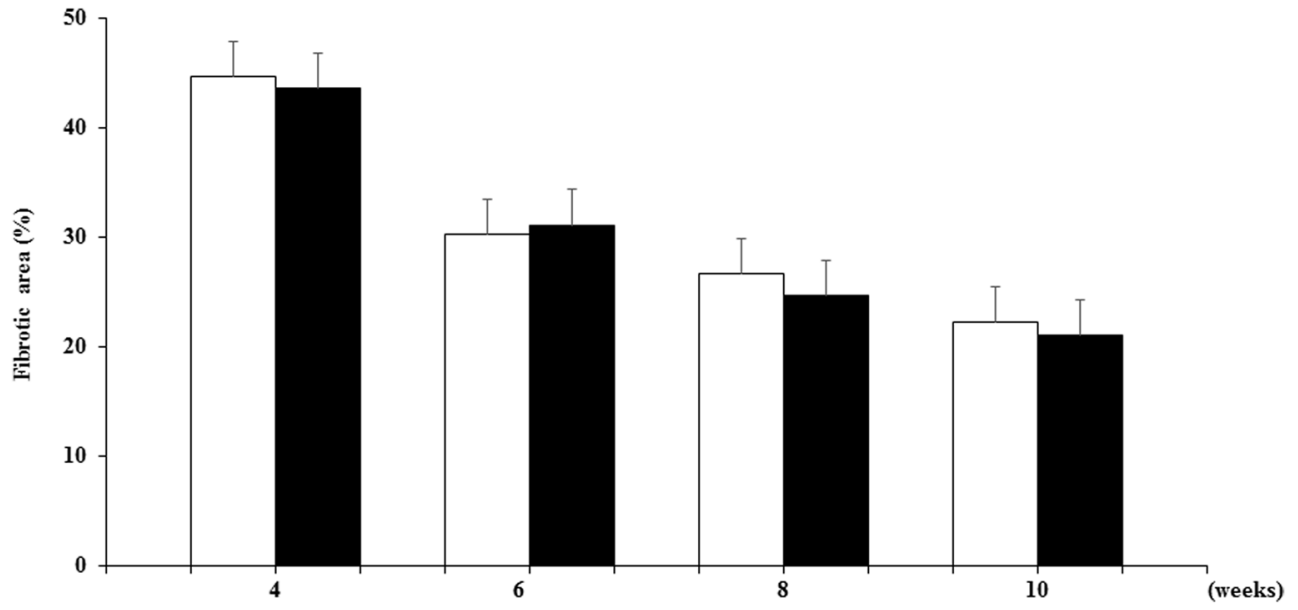

Fig. 4 a Representative cross-sections of GC muscles stained with Masson's trichrome in the non-PRP and PRP groups at 4, 6, 8, and 10 weeks after osteotomy (Bar, $100 \mu \mathrm{m})$. b The ratio of the fibrotic area to the total muscle cross sectional area in the GC muscles of the two groups. Data represent mean \pm SEM ( $n=10 /$ group/week). c Total hydroxyproline content in the GC muscles of the two groups. Data represent mean \pm SEM $(n=10 / g r o u p /$ week $)$

There are limitations in this study. Of course, this result does not correspond to the clinical scenario in patients, because there is race discrepancy between human and mouse and distraction osteogeneis procedure for mouse is not exactky same as the one for human. First limitation is that muscle function, like ankle plantarflexion torque, was not measured (Tonogai et al. 2015). Analysis for TA muscles might be also necessary. Second, osteotomy site, distraction speed, period, or length might also affect the results. Third, PRP-related factors such as variations in 
preparations and dosage, frequency of injection, or timing of injection might affect the results. The results in this study are consistent to other authors' findings that GFs in PRP were higher in their other studies. However, the absolute amount of the GFs was different, as Delos et al. reported PDGF-AB, VEGF, and TGF- $\beta 1$ concentrations in whole blood or PRP were 125 vs $330 \mathrm{pg} / \mathrm{ml}, 10$ vs $18 \mathrm{pg} /$ $\mathrm{ml} \mathrm{pg} / \mathrm{ml}$, and 32 vs $85 \mathrm{ng} / \mathrm{ml}$ respectively (Delos et al. 2014), Hammnod et al. reported that concentrations of PDGF in plasma or PRP was 4150 vs $20,745 \mathrm{pg} / \mathrm{ml}$ (Hammond et al. 2009), and Bir SC reported that concentrations of PDGF and VEGF in plasma or PRP was 30 vs $53 \mathrm{pg} / \mathrm{ml}$ and $958 \mathrm{vs} 45,352 \mathrm{pg} / \mathrm{ml}$ respectively (Bir et al. 2011). The constituents of PRP might be also affected by the condition of patients or animals before blood is harvested. Additional research is needed to define the effects of these variables and applications on PRP. Finally, skeletal muscle fibrosis in this study might be affected by the fibrosis part of the bone healing/callus to some extent.

\section{Conclusions}

In conclusion, skeletal muscle fibrosis caused by distraction osteogenesis persisted even in the GC muscles of the PRP group. At least in this study, we found no significant difference in muscle fibrosis between the PRP and non-PRP groups, and we could not show that PRP had favorable effects on skeletal muscle fibrosis. To our knowledge, this is the first report about the effect of PRP on skeletal muscle fibrosis following distraction osteogenesis. We should not use PRP for skeletal muscle following distraction osteogenesis just because PRP is a modern therapeutic approach.

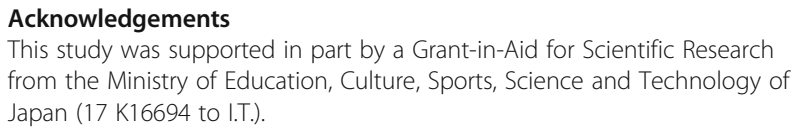

\section{Funding}

This research did not receive any specific commercial profit.

\section{Authors' contributions \\ IT designed this study, performed distraction osteogenesis for mice, and obtained samples. FH performed histological analysis. TI and TT performed molecular analysis. TM performed statistical analysis. KS advised methods of analysis of samples and coordinated this study. All authors read and approved the final manuscript.}

\section{Ethics approval}

All animal experiments were approved by the Animal Care and Use Committee of Tokushima University Graduate School and were performed according to the Guidelines for the Care and Use of Laboratory Animals at Tokushima University Graduate School (\#T29-44).

\section{Consent for publication}

All authors approved the final article.

\section{Competing interests}

The authors declare that they have no competing interests.

\section{Publisher's Note}

Springer Nature remains neutral with regard to jurisdictional claims in published maps and institutional affiliations.

Received: 20 February 2018 Accepted: 9 July 2018

Published online: 13 July 2018

\section{References}

Ali AM, El-Alfy B, Amin M, Nematalla M, El-Shafaey e-SA (2015) Can platelet-rich plasma shorten the consolidation phase of distraction osteogenesis? An experimental study. Eur J Orthop Surg Traumatol 25(3):543-548

Allen RE, Boxhorn LK (1989) Regulation of skeletal muscle satellite cell proliferation and differentiation by transforming growth factor-beta, insulin-like growth factor I, and fibroblast growth factor. J Cell Physiol 138(2):311-315

Anitua E, Sánchez M, Nurden AT, Nurden P, Orive G, Andía I (2006) New insights into and novel applications for platelet-rich fibrin therapies. Trends Biotechnol 24:227-234

Antoci V, Ono CM, Antoci V Jr, Raney EM (2006) Bone lengthening in children: how to predict the complications rate and complexity? J Pediatr Orthop 26(5):634-640

Beye JA, Hart DA, Bray RC, McDougall JJ, Salo PT (2008) Injury-induced changes in mRNA levels differ widely between anterior cruciate ligament and medial collateral ligament. Am J Sports Med 36(7):1337-1346

Bir SC, Esaki J, Marui A, Sakaguchi H, Kevil CG, Ikeda T, Komeda M, Tabata Y, Sakata R (2011) Therapeutic treatment with sustained-release platelet-rich plasma restores blood perfusion by augmenting ischemia-induced angiogenesis and arteriogenesis in diabetic mice. J Vasc Res 48(3):195-205

Border WA, Noble NA (1994) Transforming growth factor beta in tissue fibrosis. N Engl J Med 331(19):1286-1292

Borrione P, Di Gianfrancesco A, Pereira MT, Pigozzi F (2010) Platelet-rich plasma in muscle healing. Am J Phys Med Rehabil 89(10):854-861

Cianforlini M, Mattioli-Belmonte M, Manzotti S, Chiurazzi E, Piani M, Orlando F, Provinciali M, Gigante A (2015) Effect of platelet rich plasma concentration on skeletal muscle regeneration: an experimental study. J Biol Regul Homeost Agents 29(4 Suppl):47-55

Cieslik-Bielecka A, Gazdzik TS, Bielecki TM, Cieslik T (2007) Why the platelet-rich gel has antimicrobial activity? Oral Surg Oral Med Oral Pathol Oral Radiol Endod. 103:303-305

Contreras-Muñoz P, Torrella JR, Serres X, Rizo-Roca D, De la Varga M, Viscor G, Martínez-lbáñez V, Peiró JL, Järvinen TAH, Rodas G, Marotta M (2017) Postinjury exercise and platelet-rich plasma therapies improve skeletal muscle healing in rats but are not synergistic when combined. Am J Sports Med 45(9):2131-2141

Cunha RC, Francisco JC, Cardoso MA, Matos LF, Lino D, Simeoni RB, Pereira G, Irioda AC, Simeoni PR, Guarita-Souza LC, Carvalho KA (2014) Effect of plateletrich plasma therapy associated with exercise training in musculoskeletal healing in rats. Transplant Proc 46(6):1879-1881

De Deyne PG, Meyer R, Paley D, Herzenberg JE (2000) The adaptation of perimuscular connective tissue during distraction osteogenesis. Clin Orthop Relat Res 379:259-269

de Jonge S, de Vos RJ, Weir A, van Schie HT, Bierma-Zeinstra SM, Verhaar JA, Tol $J$ (2011) One-year follow-up of platelet-rich plasma treatment in chronic Achilles tendinopathy: a double-blind randomized placebo-controlled trial. Am J Sports Med 39:1623-1629

de Vos RJ, Weir A, van Schie HT, Bierma-Zeinstra SM, Verhaar JA, Weinans H, Tol $J$ (2010) Platelet-rich plasma injection for chronic Achilles tendinopathy: a randomized controlled trial. JAMA 303:144-149

Deasy BM, Feduska JM, Payne TR, Li Y, Ambrosio F, Huard J (2009) Effect of VEGF on the regenerative capacity of muscle stem cells in dystrophic skeletal muscle. Mol Ther 17(10):1788-1798

DeLong JM, Russell RP, Mazzocca AD (2012) Platelet-rich plasma: the PAW classification system. Arthroscopy 28:998-1009

Delos D, Leineweber MJ, Chaudhury S, Alzoobaee S, Gao Y, Rodeo SA (2014) The effect of platelet-rich plasma on muscle contusion healing in a rat model. Am J Sports Med 42(9):2067-2074

Fallouh L, Nakagawa K, Sasho T, Arai M, Kitahara S, Wada Y, Moriya H, Takahashi K (2010) Effects of autologous platelet-rich plasma on cell viability and collagen synthesis in injured human anterior cruciate ligament. J Bone Joint Surg Am 92:2909-2916

Gigante A, Cianforlini M, Manzotti S, Ulisse S (2014) The effects of growth factors on skeletal muscle lesions. Joints 1(4):180-186 
Gigante A, Del Torto M, Manzotti S, Cianforlini M, Busilacchi A, Davidson PA, Greco F, Mattioli-Belmonte M (2012) Platelet-rich fibrin matrix effects on skeletal muscle lesions: an experimental study. J Biol Regul Homeost Agents 26(3):475-484

Hammond JW, Hinton RY, Curl LA, Muriel JM, Lovering RM (2009) Use of autologouslatelet-rich plasma to treat muscle strain injuries. Am J Sports Med 37:1135-1142

Harris NL, Huffer WE, von Stade E, Larson Al, Phinney S, Purnell ML (2012) The effect of platelet-rich plasma on normal soft tissues in the rabbit. J Bone Joint Surg Am 94(9):786-793

Hildebrand KA, Frank CB (1998) Scar formation and ligament healing. Can J Surg 41(6):425-429

Huang S, Whang W (2010) Influence of platelet- rich plasma on proliferation and osteogenic differentiation of skeletal muscle satellite cells: an in vitro study. Oral Surg Oral Med Oral Pathol Oral Radiol Endod 110:453-462

Huard J, Li Y, Fu FH (2002) Muscle injuries and repair: current trends in research. J Bone Joint Surg Am 84(5):822-832

Ignotz RA, Massague J (1986) Transforming growth factor-beta stimulates the expression of fibronectin and collagen and their incorporation into the extracellular matrix. J Biol Chem 261:4337-4345

Ilizarov GA (1990) Clinical application of the tension-stress effect for limb lengthening. Clin Orto 250:8-26

labal J, Pepkowitz SH, Klapper E (2011) Platelet- rich plasma for the replenishment of bone. Curr Osteoporos Rep 9:258-263

Järvinen TA, Järvinen TL, Kääriäinen M, Aärimaa V, Vaittinen S, Kalimo $H$, Järvinen M (2007) Muscle injuries: optimising recovery. Best Pract Res Clin Rheumatol 21:317-331

Kelc R, Trapecar M, Gradisnik L, Rupnik MS, Vogrin M (2015) Platelet-rich plasma, especially when combined with a TGF-b inhibitor promotes proliferation, viability and myogenic differentiation of myoblasts in vitro. PLoS One 10(2):e0117302

Kitoh H, Kitakoji T, Tsuchiya H, Mitsuyama H, Nakamura H, Katoh M, Ishiguro N (2004) Transplantation of marrow-derived mesenchymal stem cells and platelet-rich plasma during distraction osteogenesis--a preliminary result of three cases. Bone 35(4):892-898

Li H, Hicks JJ, Wang L, Oyster N, Philippon MJ, Hurwitz S, Hogan MV, Huard J (2016) Customized platelet-rich plasma with transforming growth factor b1 neutralization antibody to reduce fibrosis in skeletal muscle. Biomaterials 87:147-156

Li Y, Huard J (2002) Differentiation of muscle-derived cells into myofibroblasts in injured skeletal muscle. Am J Pathol 161(3):895-907

Massagué J, Cheifetz S, Endo T, Nadal-Ginard B (1986) Type beta transforming growth factor is an inhibitor of myogenic differentiation. Proc Natl Acad Sci U S A 83(21):8206-8210

Menetrey J, Kasemkijwattana C, Day CS, Bosch P, Vogt M, Fu FH, Moreland MS, Huard J (2000) Growth factors improve muscle healing in vivo. J Bone Joint Surg Br 82:131-137

Mishra A, Woodall J Jr, Vieira A (2009) Treatment of tendon and muscle using platelet-rich plasma. Clin Sports Med 28:113-125

Molloy T, Wang Y, Murrell G (2003) The roles of growth factors in tendon and ligament healing. Sports Med 33:381-394

Moojen DJ, Everts PA, Schure RM, Overdevest EP, van Zundert A, Knape JT, Castelein RM, Creemers LB, WJ I D (2008) Antimicrobial activity of plateletleukocyte gel against Staphylococcus aureus. J Orthop Res 26:404-410

Mu X, Bellayr I, Walters T, Li Y (2010) Mediators leading to fibrosis - how to measure and control them in tissue engineering. Oper Tech Orthop 20(2):110-118

Nin JR, Gasque GM, Azcárate AV, Beola JD, Gonzalez MH (2009) Has platelet-rich plasma any role in anterior cruciate ligament allograft healing? Arthroscopy 25:1206-1213

Ota S, Uehara K, Nozaki M, Kobayashi T, Terada S, Tobita K, Fu FH, Huard J (2011) Intramuscular transplantation of muscle-derived stem cells accelerates skeletal muscle healing after contusion injury via enhancement of angiogenesis. Am J Sports Med 39(9):1912-1922

Paley D (1999) Problems, obstacles, and complications of limb lengthening by the llizarov technique. Clin Orthop Relat Res 250:81-104

Qu Z, Huard J (2000) Matching host muscle and donor myoblasts for myosin heavy chain improves myoblast transfer therapy. Gene Ther 7(5):428-437

Ranzato E, Balbo V, Boccafoschi F, Mazzucco L, Burlando B (2009) Scratch wound closure of C2C12 mouse myoblasts is enhanced by human platelet lysate. Cell Biol Int 33(9):911-917

Sanchez M, Anitua E, Azofra J, Andia I, Padilla S, Mujika I (2007) Comparison of surgically repaired Achilles tendon tears using platelet-rich fibrin matrices. Am J Sports Med 35(2):245-251
Schepull T, Kvist J, Norrman H, Trinks M, Berlin G, Aspenberg P (2011) Autologous platelets have no effect on the healing of human Achilles tendon ruptures: a randomized single-blind study. Am J Sports Med 39:38-47

Terada S, Ota S, Kobayashi M, Kobayashi T, Mifune Y, Takayama K, Witt M, Vadalà G, Oyster N, Otsuka T, Fu FH, Huard J (2013) Use of an antifibrotic agent improves the effect of platelet-rich plasma on muscle healing after injury. J Bone Joint Surg Am 95(11):980-988

Tonogai I, Takahashi M, Yukata K, Sato R, Nikawa T, Yasui N, Sairyo K (2015) Osteoactivin attenuates skeletal muscle fibrosis after distraction osteogenesis by promoting extracellular matrix degradation/remodeling. J Pediatr Orthop B 24(2):162-169

Visser LC, Arnoczky SP, Caballero O, Egerbacher M (2010) Platelet-rich fibrin constructs elute higher concentrations of transforming growth factor- $\beta 1$ and increase tendon cell proliferation over time when compared to blood clots: a comparative in vitro analysis. Vet Surg 39:811-817

Wang JH, losifidis MI, Fu FH (2006) Biomechanical basis for tendinopathy. Clin Orthop Relat Res 443:320-332

Williams P, Kyberd P, Simpson H, Kenwright J, Goldspink G (1998) The morphological basis of increased stiffness of rabbit tibialis anterior muscles during surgical limb-lengthening. J Anat 193(Pt1):131-138

Williams P, Simpson H, Kenwright J, Goldspink G (2001) Muscle fibre damage and regeneration resulting from surgical limb distraction. Cell Tissues Organs 169(4):395-400

Williams P, Simpson H, Kyler P, Kenwright J, Goldspink G (1999) Effect of rate of distraction on loss of range of joint movement, muscle stiffness, and intramuscular connective tissue content during surgical limb-lengthening: a study in the rabbit. Anat Rec 255(1):78-83

Wright-Carpenter T, Opolon P, Appell HJ, Meijer H, Wehling P, Mir LM (2004) Treatment of muscle injuries by local administration of autologous conditioned serum: animal experiments using a muscle contusion model. Int J Sports Med 25(8):582-587

Wrotniak M, Bielecki T, Gazdzik TS (2007) Current opinion about using the platelet-rich gel in orthopaedics and trauma surgery. Ortop Traumatol Rehabil 9:227-238

Zhou Y, Zhang J, Wu H, Hogan MV, Wang JH (2015) The differential effects of leukocyte-containing and pure platelet-rich plasma (PRP) on tendon stem/ progenitor cells - implications of PRP application for the clinical treatment of tendon injuries. Stem Cell Res Ther 6:173

\section{Submit your manuscript to a SpringerOpen ${ }^{\circ}$ journal and benefit from:}

- Convenient online submission

- Rigorous peer review

- Open access: articles freely available online

High visibility within the field

- Retaining the copyright to your article

Submit your next manuscript at $>$ springeropen.com 